\title{
A note on omissions and transliteration
}

Omissions to avoid repetition are marked [...].

Arabic words and phrases have been transliterated except when words, including proper names, have become familiar in English. This leads to some unavoidable inconsistencies. 
Jonathan Benthall - 9781784997458 Downloaded from manchesterhive.com at 04/26/2023 01:46:45PM via free access 